\title{
Screening of six risk exons of the RET proto-oncogene in families with medullary thyroid carcinoma in the Czech Republic
}

\author{
Š Jindřichová, J Včelák, P Vlček ${ }^{1}$, M Neradilová ${ }^{1}$, J Němec ${ }^{1}$ and \\ B Bendlová
}

Department of Molecular Endocrinology, Institute of Endocrinology, Národní 8, Prague 1, 11694 Czech Republic

${ }^{1}$ Clinic of Nuclear Medicine and Endocrinology, 2nd Medical Faculty, Charles University, V Úvalu 64, Prague 5, 15006 Czech Republic

(Requests for offprints should be addressed to Š Jindřichová; Email: sarka@obloha.cz)

\begin{abstract}
Medullary thyroid carcinoma (MTC) occurs as a sporadic form $(75 \%)$ or as an autosomal dominant inherited familial disorder (25\%) called familial MTC (FMTC) or as multiple endocrine neoplasia type 2 (MEN2) syndromes. Germ-line mutations in the rearranged during transfection (RET) proto-oncogene in exons 10,11,13,14, 15 and 16 are known to be a cause of most of the familial forms. In this paper we report molecular genetic testing of 106 families with MTC (358 tested persons) from the Czech Republic in which we directly sequenced these six exons of the RET proto-oncogene. We detected germ-line mutations in $100 \%$ of MEN2B families (4/4 families), $90 \%$ of MEN2A families (9/10), 40\% of FMTC families (4/10)
\end{abstract}

and 7\% of apparently sporadic MTC (6/82). Eleven different germ-line mutations were revealed. MEN2B was associated with mutation Met918 Thr in exon 16. In one MEN2B family beside this mutation the Tyr791 Phe was also found, which has not yet been reported. MEN2A was restricted to different mutations in exon 11 (codon 634). In FMTC and 'sporadic' MTC families the mutations in exons 10,11, 13 and 14 were detected. The genotype/ phenotype correlations are given. Genetic testing revealed germ-line mutations in 23 index patients, 24 family members and excluded them in 53 relatives.

Journal of Endocrinology (2004) 183, 257-265

\section{Introduction}

Medullary thyroid carcinoma (MTC), a rare type of tumours derived from thyroid parafollicular cells (C-cells), accounts for from $5 \%$ to $10 \%$ of all thyroid malignancies. MTC may occur as a sporadic form (75\% of cases) or, less frequently, as a hereditary disorder with an autosomal dominant mode of inheritance (25\% of cases). Three clinically hereditary forms are known: familial MTC (FMTC), multiple endocrine neoplasia type 2A (MEN2A) and type $2 \mathrm{~B}$ (MEN2B). FMTC is characterized by the familial occurrence of MTC without other lesions. MEN2A, the most frequent form, is characterized by MTC, pheochromocytoma (Pheo) in $50 \%$ of cases, and/or hyperparathyroidism (HPT) in $20 \%$ of cases. The most aggressive variant of MTC appears in conjunction with marfanoid habitus, ganglioneuromatosis, bumpy lips, diarrhoea, mucosal neuromas and Pheo (in 50\% of cases) in MEN2B syndrome. Because of the autosomal dominant mode of inheritance the offspring of the FMTC and MEN2 patients have a $50 \%$ chance of inheriting the disease.

Prospective biochemical screening for early MTC symptoms in individuals at risk is performed by measurement of basal and stimulated serum levels of calcitonin with a pentagastrin and/or calcium injection. The elevated calcitonin levels are indicative of C-cell hyperplasia or MTC (Telenius-Berg et al. 1984). Early diagnosis and surgical intervention can prevent the development of thyroid metastasis and lengthen the survival time of patients after surgery (Gagel et al. 1988). However, false positive, as well as false negative, biochemical results sometimes occur. The interpretation of elevated calcitonin levels in children is also complicated (Landsvater et al. 1993). Moreover, longterm screening is expensive and the families are subjected to extreme psychological stress.

It is well documented that germ-line activating point mutations in the rearranged during transfection (RET) proto-oncogene are associated with the pathogenesis of familial forms of MTC (Donis-Keller et al. 1993, Hofstra et al. 1994, Mulligan et al. 1994). The human RET proto-oncogene is located on chromosome $10 \mathrm{q} 11 \cdot 2$, consists of 21 exons and encodes a transmembrane receptor tyrosine kinase that plays a role in the normal development, differentiation and neoplastic growth of neural crest lineages (Ishizaka et al. 1989). In MTC patients germ-line mutations mostly occur in two main functional domains of the RET protein - in the extracellular ligand-binding domain (in MEN2A and FMTC) and in the intracellular 
catalytic tyrosine kinase domain (in MEN2B and FMTC). Approximately $92 \%$ of MEN2 syndromes are related to germ-line missense mutations of the RET proto-oncogene (Eng et al. 1996). In almost all MEN2A families mutations involve one of the six cysteines in the extracellular domain of $R E T$ encoded by exon 11 (codons 630 and 634) or exon 10 (codons 609, 611, 618, and 620) (Mulligan et al. 1995). The most frequent mutation occurs at codon 634 in exon 11 (Eng et al. 1996). The MEN2A mutations result probably in modulation of receptor disulfide dimerization, whereas the MEN2B mutations alter the RET catalytic properties (Santoro et al. 1995). MEN2B is caused by the mutation Met918 Thr in exon 16 in the tyrosine kinase domain of the RET (Hofstra et al. 1994). Rare causes of MEN2B are mutations in exon 15 at codon 883 and in exon 16 at codon 922 (Kitamura et al. 1995, Smith et al. 1997). In FMTC families RET mutations affect either one of the cysteine codons in exons 10 or 11 or, less frequently, codons 768, 790, or 791 (exon 13), codon 804 (exon 14), or codon 891 (exon 15) in the tyrosine kinase domain or codon 533 in exon 8 in the extracellular domain (Bolino et al. 1995, Eng et al. 1995a, Fattoruso et al. 1998, Da Silva et al. 2003).

Specific mutations in different codons may influence the phenotypic expression. The mutations involving codon 634, the substitution of cysteine for arginine, is significantly predictive for the development of Pheo and parathyroid disease (Mulligan et al. 1994, Schuffenecker et al. 1994). Some mutations could represent milder variants of the disease, as in exons 13 and 14 (Fitze et al. 2002, Lombardo et al. 2002). Recently, in some MEN2 families, other clinical features have been described such as Hirschsprung's disease (HSCR) or cutaneous lichen amyloidosis (CLA) (Borst et al. 1995, Verga et al. 2003).

The identification of the RET proto-oncogene mutations responsible for MEN2 syndrome provides the opportunity to find mutation carriers in families at risk and simplifies the management of kindreds with this disease. The prophylactic total thyroidectomy can be performed at a very early stage of the disease. Therefore, the morbidity and mortality of these patients is markedly reduced. The traditional MEN2A and FMTC categories could be, thanks to genetics, updated and reclassified (Machens et al. 2001) and some familial cases can be found among apparently sporadic MTC families.

The aim of this study was to determine frequency and position of the germ-line mutations in exons $10,11,13$, 14, 15 and 16 and to correlate the genotype with disease phenotype in a large cohort of 106 Czech MTC families.

\section{Materials and Methods}

\section{MTC families}

We collected 106 unrelated MTC families (106 index cases and their relatives, a total of 358 persons tested) selected from the population of the Czech Republic (10 million). The index patients were clinically and biochemically characterized and classified as sporadic MTC (82 families/235 tested persons), FMTC (10/62), MEN2A $(10 / 50)$ and MEN2B (4/11). We considered FMTC as families with one index patient and at least one other family member who was operated on on the basis of elevated calcitonin levels and C-cell hyperplasia or where MTC was histologically confirmed. Due to the small family sizes it was not possible to fulfil the strict International RET Mutation Consortium criteria for FMTC that suggests at least four cases of MTC per family (Eng et al. 1996).

\section{Clinical and biochemical screening}

MTC or C-cell hyperplasia was determined on the basis of increased basal and stimulated calcitonin levels and histologically confirmed by pathologists after an operation. The basal and pentagastrin-Ca stimulated calcitonin levels were performed with RIA kit (DSL-1200, Webster, TX, USA). Basal and stimulated calcitonin values below $40 \mathrm{pg} / \mathrm{ml}$ and $200 \mathrm{pg} / \mathrm{ml}$ respectively were considered normal. All positive probands were screened for the presence of Pheo by measurement of blood pressure, plasma and/or urinary levels of catecholamines using HPLC methods. Screening for HPT was performed by measuring serum calcium and parathyroid hormone levels.

\section{Molecular genetic analysis}

Before genetic testing, all patients had given their informed consent in accordance with institutional ethics guidelines and national regulations. Pedigrees were created by the Cyrillic programme, Family Genetix, Oxford, UK. Molecular analyses were carried out on 106 index patients and, in mutation positive cases, their relatives at risk of the disease were also screened. Molecular genetic data were then correlated with phenotype, sex, age at diagnosis, Primary tumor, Regional Lymph Nodes, Distant Metastasis (TNM) classification, tumorous foci, laterality, presence of Pheo and other clinical features were obtained from the patients' anamnesis.

Genomic DNA was isolated from peripheral blood leukocytes using phenol-chloroform extraction, precipitated with ethanol and dissolved in TE buffer. At present, the NucleoSpin Blood kit (Macherey-Nagel, Duren, Germany) is used for isolation of DNA. After measurement of the DNA concentration and DNA/protein ratio, the DNA was used for PCR amplification.

Genomic DNA was amplified using PCR. The primers for exons 10,11, 13, 14, 15 and 16 are given in Table 1. All reactions were performed in $30 \mu \mathrm{l}$ containing $10 \mathrm{mM}$ Tris- $\mathrm{HCl} \mathrm{pH} 8 \cdot 3,50 \mathrm{mM} \mathrm{KCl}, 160 \mu \mathrm{M}$ dNTPs, $0 \cdot 1 \mu \mathrm{M}$ of each primer, $0.45 \mathrm{U}$ Gold AmpliTaq polymerase (Perkin Elmer, Langen, Germany), 60 ng DNA and 
optimalized concentration of $\mathrm{MgCl}_{2}$ (Table 1). The running profile of the amplifications was: initial denaturation at $95{ }^{\circ} \mathrm{C}$ for $10 \mathrm{~min}$ followed by 40 cycles (denaturation at $95^{\circ} \mathrm{C}$ for $30 \mathrm{~s}$, annealing at optimalized temperature (Table 1) for $30 \mathrm{sec}$, elongation at $72{ }^{\circ} \mathrm{C}$ for $1 \mathrm{~min}$ ) and final elongation at $72{ }^{\circ} \mathrm{C}$ for $10 \mathrm{~min}$ (thermocycler; Biometra, Goettingen, Germany). PCR products were analyzed by $1.5 \%$ agarose Tris-borate-EDTA gel electrophoresis. The gel was stained with ethidium bromide and analyzed under u.v. light. A negative control was included in each amplification analysis.

Sequencing of 6 exons in the sense and antisense directions was carried out on the ALF-express gel sequencing machine (Pharmacia, Uppsala, Sweden). For the sequenase reaction the previously purified matrix PCR products (GenElute Gel purification kit, Sigma, St Louis, MO, USA), the fluorescent (Cy5)-labelled primers (Table 1) and the Thermo-sequenase Cycle Sequencing kit (USB, Cleveland, OH, USA) were used.

\section{Results}

\section{Detected mutations}

We examined 106 unrelated families suffering from MTC and found germ-line mutations in 23 of them (Table 2). We detected 11 different types of mutations in the RET proto-oncogene in exons 10,11,13,14 and 16 (in one family a double mutation in exons 13 and 16 was found). No mutation in exon 15 was found. The prevalences of mutations were: $47 \cdot 8 \%$ in exon 11 (eleven families), $17 \cdot 4 \%$ in exon 13 (four families), $13.0 \%$ in exon 14 (three families), $17 \cdot 4 \%$ in exon 16 (four families) and $8 \cdot 7 \%$ in exon 10 (two families). Among mutations in exon 11, the most frequent amino acid replacement was Cys634 Arg (63.6\%, seven out of 11 families).

MEN2B phenotype was associated with the mutation in exon 16 at a single codon 918. In one MEN2B family, beside this mutation, the mutation in exon 13 at codon 791 was also found. MEN2A phenotype was restricted to mutations in exon 11 at codon 634 but there were different amino acid substitutions: replacements of cysteine with arginine, serine, tryptophan or tyrosine. More varied mutations were connected with the FMTC phenotype, where mutations in exons 11, 13 and 14 were detected. The majority of FMTC mutations (75\%) were found in non-cysteine codons. In apparently sporadic MTC, germ-line mutations in exons 10,11, 13 and 14 were also found (the distribution between cysteine and non-cysteine mutations was equal).

\section{Detection rate}

Table 3 shows the detection rate in our series of patients. Among 252 relatives, 24 inherited the mutation (RET+ carriers) and 53 people were wild type RET carriers (RET - carriers) and they could therefore be excluded from further clinical screening. Fourteen carriers of mutation had high plasma calcitonin levels and had been operated on and 10 carriers are still without sign of MTC (one with a mutation in the exon 10 and nine with low penetrance in exons 13 and 14).

Clinical characteristics of index patients and persons at risk of MTC with positive testing

Table 4 shows the clinical behaviour of mutations in index patients. The female/male ratio is $2 \cdot 3$. The median ages at diagnosis differed with the type of affected exons. Median age at diagnosis in index patients with mutations in exon 16 was $20 \cdot 5$ yrs (14-31 yrs); in exon 10, 28 yrs (21 and 35 yrs); in exon 11, 28 yrs (18-47 yrs); in exon 13, 44 yrs (40 and 48 yrs) and in exon 14, 49 yrs (46-52 yrs). Milder tumour behaviour is connected with mutations in exons 13 and 14. All patients with mutations in exon 16 have the characteristic MEN2B phenotype (tall thin body habitus, long thin arms and legs, thick bumpy lips and mucosal neuromas), diarrhoea and neurofibromatosis. The biochemical and, more recently, the molecular genetic screening carried out on the cohort of relatives of index patients revealed 24 persons with positive biochemical and/or genetic tests, but only 14 of them were operated on until now. Their clinical characteristics are given in Table 5 . The female/male ratio is $1 \cdot 0$. The median age at operation is $17 \mathrm{yrs}$. In comparison with index patients, carriers have lower TNM classification due to prophylactic total thyroidectomy based on biochemical or genetic screening.

\section{Discussion}

This is the first comprehensive report of molecular genetic screening of MTC families in the Czech Republic. This set of patients does not overlap with those previously reported in the International RET Mutation Consortium and EUROMEN study group (Mulligan et al. 1995, Eng et al. 1996, Machens et al. 2003). Identification of the mutations in the RET proto-oncogene confirms the clinical diagnosis and identifies asymptomatic family members with FMTC or MEN2 syndrome. Germ-line mutations were found in $22 \%$ of these probands of all MTC families. This result is in agreement with the data stating that up to $25 \%$ of MTC cases are inherited (Egawa et al. 1998, Klein et al. 2001). Genetic testing of our 106 MTC families revealed germ-line mutations in the RET proto-oncogene in 23 index patients and in 24 relatives and excluded the germ-line mutation in 53 family members.

In agreement with data from other countries (Mulligan et al. 1994, Schuffenecker et al. 1994, Frank-Raue et al. 1996, Sanchez et al. 1999, Machens et al. 2001, 2003, 


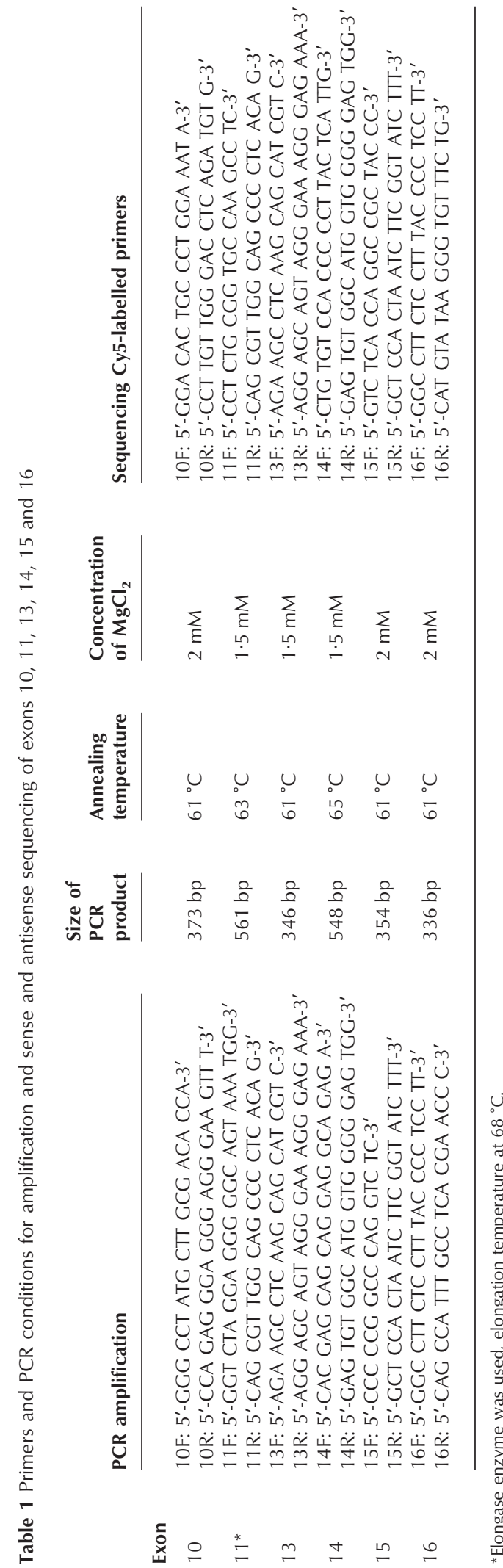


Table 2 Detected mutations in 23 RET + families

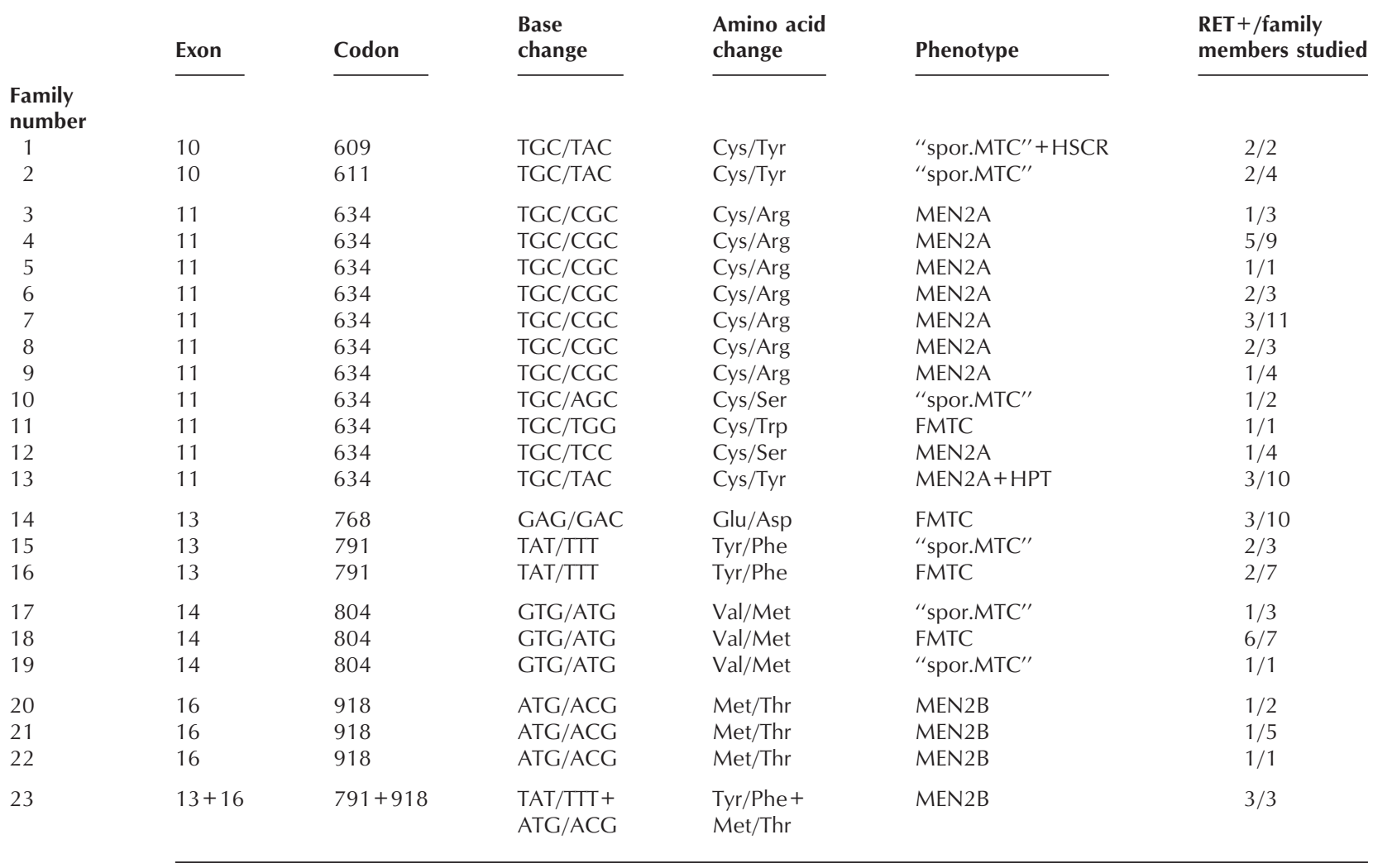

RET+, includes index patients; HSCR, Hirschsprung's disease.

Table 3 Detection rate of the set of Czech MTC families

\begin{tabular}{|c|c|c|c|c|c|}
\hline & \multicolumn{5}{|c|}{ Phenotypes } \\
\hline & spor.MTC & FMTC & MEN2A & MEN2B & Total \\
\hline $\begin{array}{l}\text { Total number of families } \\
\text { RET+ families (\%) }\end{array}$ & $\begin{array}{l}82 \\
6(7 \%)\end{array}$ & $\begin{array}{l}10 \\
4(40 \%)\end{array}$ & $\begin{array}{l}10 \\
9(90 \%)\end{array}$ & $\begin{array}{l}4 \\
4(100 \%)\end{array}$ & $\begin{array}{l}106 \\
23(22 \%)\end{array}$ \\
\hline Number of index patients & 82 & 10 & 10 & 4 & 106 \\
\hline RET+ index patients & 6 & 4 & 9 & 4 & 23 \\
\hline No mutation found & 76 & 6 & 1 & 0 & 83 \\
\hline Number of relatives & 153 & 52 & 40 & 7 & 252 \\
\hline RET+ carriers & 3 & 9 & 10 & 2 & 24 \\
\hline RET - carriers & 6 & 13 & 29 & 5 & 53 \\
\hline No mutation found & 144 & 30 & 1 & 0 & 175 \\
\hline
\end{tabular}

*RET - carriers, persons excluded from further clinical screening.

Niccoli-Sire et al. 2001, Punales et al. 2003) the most frequent mutations were found in exon 11 at codon 634 (47.8\%), mainly the replacement Cys634 Arg was present. Nine out of 10 MEN2A families were positive for point mutations exclusively involving codon 634. In one FMTC family the Cys634 Trp mutation was detected, which is usually described as a cause of MEN2A (Hansford \& Mulligan 2000). It could be explained by the misclassifi- cation of MEN2A with low penetrance of Pheo or there could be an influence of RET polymorphisms or other modifier genes that protect the FMTC from the development of Pheo (Robledo et al. 2003).

In the FMTC families our detection rate is only $40 \%$, probably due to the application of milder clinical-genetic criteria for this group. In unsolved families, the disease could still be a part of an inherited syndrome where the 
Table 4 Clinical features of RET+ index patients

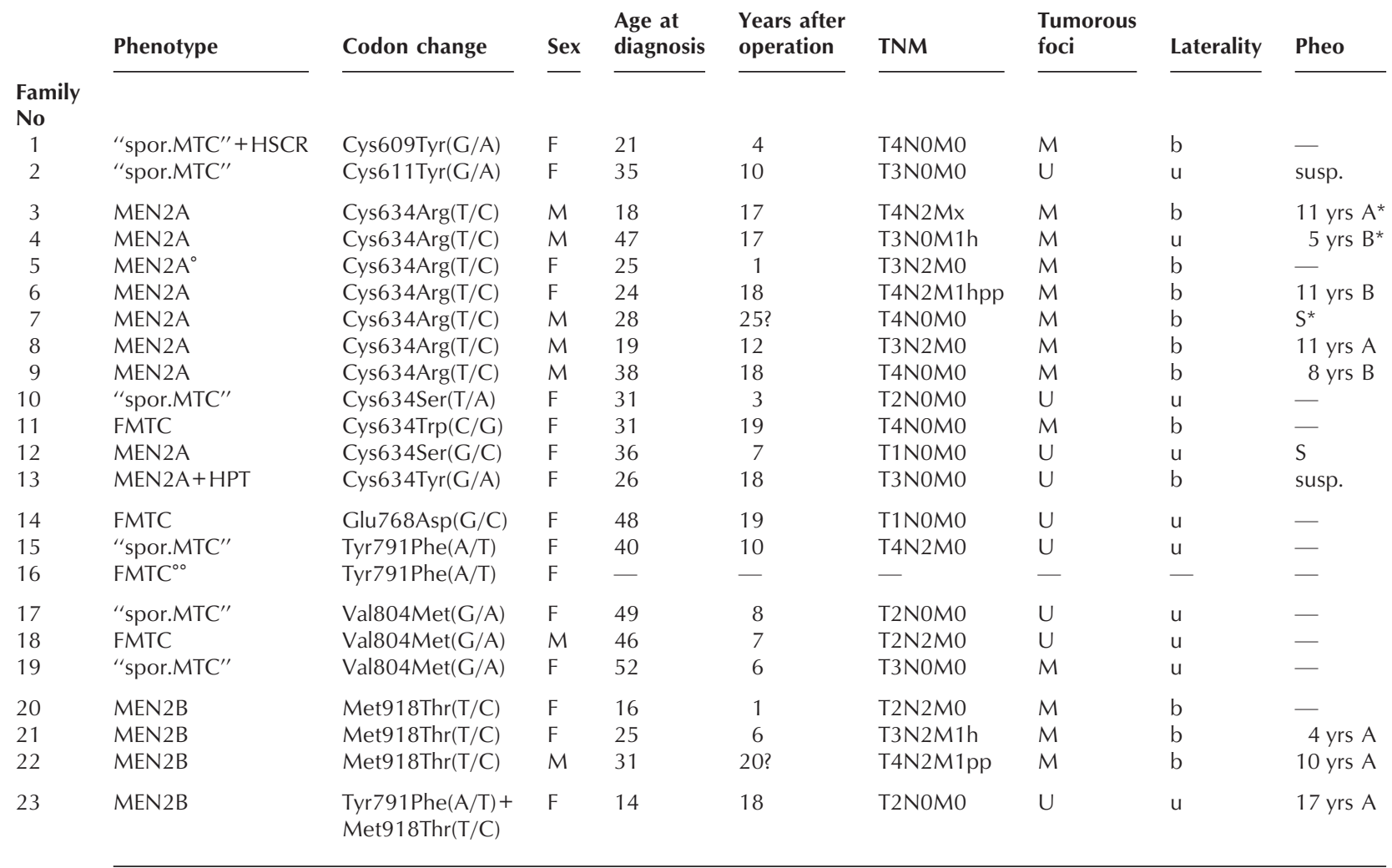

${ }^{\circ}$, Pheo was diagnosed in index patient's mother, who died due to Pheo; ${ }^{\circ}$, this patient was diagnosed abroad; *, how many years after $(\mathrm{A})$, before $(\mathrm{B})$ or at the same time as (S) total thyroidectomy operation that Pheo was operated on; $M$, multifoci; $U$, unifoci; b, bilateral; $u$, unilateral; ?, dead; susp., suspected Pheo (higher levels of catecholamines).

mutation may occur in the other exons of the RET proto-oncogene (Pigny et al. 1999, Da Silva et al. 2003); the inheritance of some mutations lying in other genes also cannot be excluded (Gil et al. 2002). FMTC families with mild clinical behaviour have non-cysteine mutations in exons 13 and 14 (Fitze et al. 2002, Lombardo et al. 2002).

A single point mutation Met918 Thr was identified in all patients with the MEN2B syndrome. Besides this mutation the second germ-line mutation in exon 13 was detected in one MEN2B family. The clinical relevance of this double mutation is not clear. Usually, mutations in exon 13 are connected with less aggressive forms of MTC. Therefore, this second mutation could be responsible for postponing the development of Pheo. This patient was operated on for Pheo 17 years after the total thyroidectomy. This double mutation in MEN2B family has not been observed previously but the double mutation in exon 14 (codons 804 and 806) causing MEN2B phenotype has been published (Kitamura et al. 1995, Menko et al. 2002).

We confirmed that the genetic screening is very useful in 'sporadic' MTC families. The germ-line mutations (in exons $10,11,13,14)$ were detected in $7 \%$ of these families (Eng et al. 1995b, Wohllk et al. 1996, Scurini et al. 1998). They could have been misclassified due to the small family number and poor family data or due to the occurrence of de novo germ-line mutations. In one apparently sporadic MTC family we found an asymptomatic carrier (the patient's mother) with germline mutation Cys609 Tyr. The relatively small number of our samples does not allow us to draw widespread conclusions on phenotype/ genotype correlations. But, according to the literature, the presence of mutations at codon 634 is associated with a higher risk of Pheo (Eng et al. 1996, Yip et al. 2003). However, no specific mutation was associated with this predisposition. Age at diagnosis was related to a specific exon and unrelated to a specific nucleotide and amino acid exchange within each codon according to Machens (Machens et al. 2001, Machens et al. 2003). We confirmed that exons 13 and 14 present a less aggressive disease, where age at diagnosis ranges between 40 and 50 yrs of age, whereas mutations in exons 10,11 and 16 are linked with a much younger age at diagnosis (20-30 yrs). Hirschsprung's disease (loss of the RET function) was identified in one MTC family where the mutation in exon 
Table 5 Clinical features of RET+ relatives who underwent the total thyroidectomy due to the positive biochemical and/or genetic tests

\begin{tabular}{|c|c|c|c|c|c|c|c|c|c|}
\hline & Phenotype & Codon & Sex & $\begin{array}{l}\text { Age at } \\
\text { operation }\end{array}$ & $\begin{array}{l}\text { Years after } \\
\text { operation }\end{array}$ & TNM & $\begin{array}{l}\text { Tumorous } \\
\text { foci }\end{array}$ & Laterality & Pheo \\
\hline \multicolumn{10}{|c|}{ Family } \\
\hline 2 & "spor.MTC" & Cys611Tyr(G/A) & $\mathrm{F}$ & 15 & 1 & T1N0M0 & $U$ & $\mathrm{u}$ & - \\
\hline 4 & MEN2A & Cys634Arg(T/C) & M & 9 & 4 & T2NOMO & M & $\mathrm{u}$ & - \\
\hline 4 & MEN2A & Cys634Arg(T/C) & $\mathrm{F}$ & 21 & 17 & T2NOMO & M & $\mathrm{u}$ & susp. \\
\hline 4 & MEN2A & Cys634Arg(T/C) & $\mathrm{F}$ & 22 & 18 & T3N2M1hh, colon & M & b & $5 \mathrm{yrs}^{\circ}$ \\
\hline 4 & MEN2A & Cys634Arg(T/C) & M & 7 & 0 & T1N0M0 & $U$ & $\mathrm{u}$ & - \\
\hline 6 & MEN2A & Cys634Arg(T/C) & M & 8 & 13 & T1N0M0 & $U$ & $\mathrm{u}$ & susp. \\
\hline 7 & MEN2A & Cys634Arg(T/C) & $\mathrm{F}$ & 9 & 21 & T1N0M0 & $U$ & $\mathrm{u}$ & susp. \\
\hline 7 & MEN2A & Cys634Arg(T/C) & $\mathrm{F}$ & 22 & 26 & T3NOMO & $U$ & $u$ & 15 yrs A \\
\hline 8 & MEN2A & Cys634Arg(T/C) & M & 43 & 11 & T2NOMO & $U$ & $\mathrm{u}$ & susp. \\
\hline 13 & MEN2A+HPT & Cys634Tyr(G/A) & M & 19 & 5 & T2N0M0 & M & $\mathrm{u}$ & - \\
\hline 13 & MEN2A+HPT & Cys634Tyr(G/A) & $\mathrm{F}$ & 25 & 2 & T1N0M1h & $U$ & $\mathrm{u}$ & susp. \\
\hline 14 & FMTC & Glu768Asp(G/C) & $\mathrm{F}$ & 51 & 18 & T1N0M0 & $U$ & $\mathrm{u}$ & - \\
\hline 23 & MEN2B & $\begin{array}{l}\text { Tyr791Phe(A/T)+ } \\
\text { Met918Thr(T/C) }\end{array}$ & M & 7 & 5 & T1N1M0 & $U$ & $\mathrm{u}$ & - \\
\hline 23 & MEN2B & $\begin{array}{l}\text { Tyr791Phe(A/T)+ } \\
\text { Met918Thr(T/C) }\end{array}$ & M & 5 & 2 & T1N0M0 & $U$ & $\mathrm{u}$ & - \\
\hline
\end{tabular}

Ten other RET + relatives are still without sign of MTC (one has mutation in exon 10 and will be operated on this year. The other nine relatives have less aggressive mutations in exons 13 and 14 still with normal levels of calcitonin and without ultrasound findings). M, multifoci; $U$, unifoci; b, bilateral; $u$, unilateral, , how many years after (A) total thyroidectomy operation Pheo was operated on; susp., suspected Pheo (higher levels of catecholamines).

10 at codon 609 was detected. Hirschsprung's disease mostly segregates with codons 620 and 618 in exon 10 (Pasini et al. 2002). In one MEN2A family with a mutation in exon 11 at codon $634 \mathrm{HPT}$ was detected. It represents the occurrence of HPT in 10\% of our MEN2A families, which corresponds to the literature (Karga et al. 1998).

It is evident that biochemical and genetic screening in family relatives helped to decrease the TNM stage and changed MTC characteristics to unifocal and unilateral (Frilling et al. 1995, Pacini et al. 1995, Sanso et al. 2002) but it did not influence the development of Pheo.

Our laboratory is now responsible for the MTC molecular genetic diagnostic programme in the Czech Republic. The programme covers all Czech MTC patients and their families at present. It was confirmed that genetic screening is a valuable tool for identification of predisposed individuals in families at risk.

\section{Acknowledgements}

This study was supported by the grants IGA Ministry of Health CR NC/6650-3 and NR/7806-3. There is no conflict of interest that could prejudice the impartiality of this scientific work. We are very grateful to the Czech endocrinologists, surgeons, pathologists and clinical as well as technical assistants who made a valuable contribution to this research. We thank the patients and their families for their participation in this study. We also thank Ing. Petr Dvoŕak for his assistance in the preparation of this manuscript.

\section{References}

Bolino A, Schuffenecker I, Luo Y, Seri M, Silengo M, Tocco T, Chabrier G, Houdent C, Murat A, Schlumberger M et al. 1995 RET mutations in exons 13 and 14 of FMTC patients. Oncogene 10 2415-2419.

Borst MJ, VanCamp JM, Peacock ML \& Decker RA 1995 Mutational analysis of multiple endocrine neoplasia type $2 \mathrm{~A}$ associated with Hirschsprung's disease. Surgery 117 386-391.

Da Silva AM, Maciel RM, Da Silva MR, Toledo SR, De Carvalho MB \& Cerutti JM 2003 A novel germ-line point mutation in RET exon 8 (Gly(533)Cys) in a large kindred with familial medullary thyroid carcinoma. Journal of Clinical Endocrinology and Metabolism $\mathbf{8 8}$ 5438-5443.

Donis-Keller H, Dou S, Chi D, Carlson KM, Toshima K, Lairmore TC, Howe JR, Moley JF, Goodfellow P \& Wells SA Jr 1993 Mutations in the RET proto-oncogene are associated with MEN 2A and FMTC. Human Molecular Genetics 2 851-856.

Egawa S, Futami H, Takasaki K, Iihara M, Okamoto T, Kanbe M, Ohi T, Saio Y, Miyauchi A, Takiyama Y et al. 1998 Genotypephenotype correlation of patients with multiple endocrine neoplasia type 2 in Japan. Japanese Journal of Clinical Oncology 28 590-596.

Eng C, Mulligan LM, Smith DP, Healey CS, Frilling A, Raue F, Neumann HP, Pfragner R, Behmel A, Lorenzo MJ et al. 1995a Mutation of the RET protooncogene in sporadic medullary thyroid carcinoma. Genes, Chromosomes and Cancer 12 209-212.

Eng C, Smith DP, Mulligan LM, Healey CS, Zvelebil MJ, Stonehouse TJ, Ponder MA, Jackson CE, Waterfield MD \& Ponder BA 1995b A novel point mutation in the tyrosine kinase domain of the RET proto-oncogene in sporadic medullary thyroid carcinoma and in a family with FMTC. Oncogene 10 509-513.

Eng C, Clayton D, Schuffenecker I, Lenoir G, Cote G, Gagel RF, van Amstel HK, Lips CJ, Nishisho I, Takai SI et al. 1996 The relationship between specific RET proto-oncogene mutations and disease phenotype in multiple endocrine neoplasia type 2 . International RET mutation consortium analysis. Journal of the American Medical Association 276 1575-1579.

Journal of Endocrinology (2004) 183, 257-265 
Fattoruso O, Quadro L, Libroia A, Verga U, Lupoli G, Cascone E \& Colantuoni V 1998 A GTG to ATG novel point mutation at codon 804 in exon 14 of the RET proto-oncogene in two families affected by familial medullary thyroid carcinoma. Human Mutation (Suppl 1) 167-171.

Fitze G, Schierz M, Bredow J, Saeger HD, Roesner D \& Schackert HK 2002 Various penetrance of familial medullary thyroid carcinoma in patients with RET protooncogene codon 790/791 germline mutations. Annals of Surgery 236 570-575.

Frank-Raue K, Hoppner W, Frilling A, Kotzerke J, Dralle H, Haase R, Mann K, Seif F, Kirchner R, Rendl J et al. 1996 Mutations of the Ret protooncogene in German multiple endocrine neoplasia families: relation between genotype and phenotype. German Medullary Thyroid Carcinoma Study Group. Journal of Clinical Endocrinology and Metabolism 81 1780-1783.

Frilling A, Hoppner W, Eng C, Mulligan L, Raue F \& Broelsch CE 1995 Presymptomatic genetic screening in families with multiple endocrine neoplasia type 2. Journal of Molecular Medicine $\mathbf{7 3}$ 229-233.

Gagel RF, Tashjian AH Jr, Cummings T, Papathanasopoulos N, Kaplan MM, DeLellis RA, Wolfe HJ \& Reichlin S 1988 The clinical outcome of prospective screening for multiple endocrine neoplasia type 2a. An 18-year experience. New England Journal of Medicine 318 478-484.

Gil L, Azanedo M, Pollan M, Cristobal E, Arribas B, Garcia-Albert L, Garcia-Saiz A, Maestro ML, Torres A, Menarguez J et al. 2002 Genetic analysis of RET, GFR alpha 1 and GDNF genes in Spanish families with multiple endocrine neoplasia type $2 \mathrm{~A}$. International Journal of Cancer 99 299-304.

Hansford JR \& Mulligan LM 2000 Multiple endocrine neoplasia type 2 and RET: from neoplasia to neurogenesis. Journal of Medical Genetics 37 817-827.

Hofstra RM, Landsvater RM, Ceccherini I, Stulp RP, Stelwagen T, Luo Y, Pasini B, Hoppener JW, van Amstel HK \& Romeo G 1994 A mutation in the RET proto-oncogene associated with multiple endocrine neoplasia type $2 \mathrm{~B}$ and sporadic medullary thyroid carcinoma. Nature 367 375-376.

Ishizaka Y, Itoh F, Tahira T, Ikeda I, Sugimura T, Tucker J, Fertitta A, Carrano AV \& Nagao M 1989 Human Ret proto-oncogene mapped to chromosome 10q11.2. Oncogene 4 1519-1521.

Karga HJ, Karayianni MK, Linos DA, Tseleni SC, Karaiskos KD \& Papapetrou PD 1998 Germ line mutation analysis in families with multiple endocrine neoplasia type $2 \mathrm{~A}$ or familial medullary thyroid carcinoma. European Journal of Endocrinology 139 410-415.

Kitamura Y, Scavarda N, Wells SA Jr, Jackson CE \& Goodfellow PJ 1995 Two maternally derived missense mutations in the tyrosine kinase domain of the RET protooncogene in a patient with de novo MEN2B. Human Molecular Genetics 5 1987-1988.

Klein I, Esik O, Homolya V, Szeri F \& Varadi A 2001 Molecular genetic diagnostic program of multiple endocrine neoplasia type $2 \mathrm{~A}$ and familial medullary thyroid carcinoma syndromes in Hungary. Journal of Endocrinology 170 661-666.

Landsvater RM, Rombouts AG, te Meerman GJ, Schillhorn-van Veen JM, Berends MJ, Geerdink RA, Struyvenberg A, Buys CH \& Lips CJ 1993 The clinical implications of a positive calcitonin test for C-cell hyperplasia in genetically unaffected members of an MEN2A kindred. American Journal of Human Genetics 52 335-342.

Lombardo F, Baudin E, Chiefari E, Arturi F, Bardet S, Caillou B, Conte C, Dallapiccola B, Giuffrida D, Bidart JM et al. 2002 Familial medullary thyroid carcinoma: clinical variability and low aggressiveness associated with RET mutation at codon 804. Journal of Clinical Endocrinology and Metabolism 87 1674-1680.

Machens A, Gimm O, Hinze R, Hoppner W, Boehm BO \& Dralle H 2001 Genotype-phenotype correlations in hereditary medullary thyroid carcinoma: oncological features and biochemical properties. Journal of Clinical Endocrinology and Metabolism 86 1104-1109.

Machens A, Niccoli-Sire P, Hoegel J, Frank-Raue K, van Vroonhoven TJ, Roeher HD, Wahl RA, Lamesch P, Raue F,
Conte-Devolx B et al. 2003 Early malignant progression of hereditary medullary thyroid cancer. New England Journal of Medicine 349 1517-1525.

Menko FH, van der Luijt RB, de Valk IA, Toorians AW, Sepers JM, van Diest PJ \& Lips CJ 2002 Atypical MEN type 2B associated with two germline RET mutations on the same allele not involving codon 918. Journal of Clinical Endocrinology and Metabolism $\mathbf{8 7}$ 393-397.

Mulligan LM, Eng C, Healey CS, Clayton D, Kwok JB, Gardner E, Ponder MA, Frilling A, Jackson CE, Lehnert H et al. 1994 Specific mutations of the RET proto-oncogene are related to disease phenotype in MEN 2A and FMTC. Nature Genetics 6 70-74.

Mulligan LM, Marsh DJ, Robinson BG, Schuffenecker I, Zedenius J, Lips CJ, Gagel RF, Takai SI, Noll WW \& Fink M 1995 Genotype-phenotype correlation in multiple endocrine neoplasia type 2: report of the International RET Mutation Consortium. Journal of Internal Medicine 238 343-346.

Niccoli-Sire P, Murat A, Rohmer V, Franc S, Chabrier G, Baldet L, Maes B, Savagner F, Giraud S, Bezieau S et al. 2001 Familial medullary thyroid carcinoma with noncysteine ret mutations: phenotype-genotype relationship in a large series of patients. Journal of Clinical Endocrinology and Metabolism 86 3746-3753.

Pacini F, Romei C, Miccoli P, Elisei R, Molinaro E, Mancusi F, Iacconi P, Basolo F, Martino E \& Pinchera A 1995 Early treatment of hereditary medullary thyroid carcinoma after attribution of multiple endocrine neoplasia type 2 gene carrier status by screening for Ret gene mutations. Surgery 118 1031-1035.

Pasini B, Rossi R, Ambrosio MR, Zatelli MC, Gullo M, Gobbo M, Collini P, Aiello A, Pansini G Trasforini G et al. 2002 RET mutation profile and variable clinical manifestations in a family with multiple endocrine neoplasia type 2A and Hirschsprung's disease. Surgery 131 373-381.

Pigny P, Bauters C, Wemeau JL, Houcke ML, Crepin M, Caron P, Giraud S, Calender A, Buisine MP, Kerckaert JP et al. 1999 A novel 9-base pair duplication in RET exon 8 in familial medullary thyroid carcinoma. Journal of Clinical Endocrinology and Metabolism 84 1700-1704.

Punales MK, Graf H, Gross JL \& Maia AL 2003 RET codon 634 mutations in multiple endocrine neoplasia type 2: variable clinical features and clinical outcome. Journal of Clinical Endocrinology and Metabolism 88 2644-2649.

Robledo M, Gil L, Pollan M, Cebrian A, Ruiz S, Azanedo M, Benitez J, Menarguez J \& Rojas JM 2003 Polymorphisms G691S/S904S of RET as genetic modifiers of MEN 2A. Cancer Research 63 1814-1817.

Sanchez B, Robledo M, Biarnes J, Saez ME, Volpini V, Benitez J, Navarro E, Ruiz A, Antinolo G \& Borrego S 1999 High prevalence of the C634Y mutation in the RET proto-oncogene in MEN 2A families in Spain. Journal of Medical Genetics 36 68-70.

Sanso GE, Domene HM, Garcia R, Pusiol E, de Mondino, Roque M, Ring A, Perinetti H, Elsner B, Iorcansky S et al. 2002 Very early detection of RET proto-oncogene mutation is crucial for preventive thyroidectomy in multiple endocrine neoplasia type 2 children: presence of $\mathrm{C}$-cell malignant disease in asymptomatic carriers. Cancer 94 323-330.

Santoro M, Carlomagno F, Romano A, Bottaro DP, Dathan NA, Grieco M, Fusco A, Vecchio G, Matoskova B \& Kraus MH 1995 Activation of RET as a dominant transforming gene by germline mutations of MEN 2A and MEN 2B. Science 267 381-383.

Schuffenecker I, Billaud M, Calender A, Chambe B, Ginet N, Calmettes C, Modigliani E \& Lenoir GM 1994 RET proto-oncogene mutations in French MEN 2A and FMTC families. Human Molecular Genetics 3 1939-1943.

Scurini C, Quadro L, Fattoruso O, Verga U, Libroia A, Lupoli G, Cascone E, Marzano L, Paracchi S, Busnardo B et al. 1998 Germline and somatic mutations of the RET proto-oncogene in apparently sporadic medullary thyroid carcinomas. Molecular and Cellular Endocrinology 137 51-57. 
Smith DP, Houghton C \& Ponder BA 1997 Germline mutation of RET codon 883 in two cases of de novo MEN 2B. Oncogene 15 1213-1217.

Telenius-Berg M, Berg B, Hamberger B, Tibblin S, Tisell LE, Ysander L \& Welander G 1984 Impact of screening on prognosis in the multiple endocrine neoplasia type 2 syndromes: natural history and treatment results in 105 patients. Henry Ford Hospital Medical Journal 32 225-231.

Verga U, Fugazzola L, Cambiaghi S, Pritelli C, Alessi E, Cortelazzi D, Gangi E \& Beck-Peccoz P 2003 Frequent association between MEN2A and cutaneous lichen amyloidosis. Clinical Endocrinology (Oxford) 59 156-161.
Wohllk N, Cote GJ, Bugalho MM, Ordonez N, Evans DB, Goepfert H, Khorana S, Schultz P, Richards CS \& Gagel RF 1996

Relevance of RET proto-oncogene mutations in sporadic medullary thyroid carcinoma. Journal of Clinical Endocrinology and Metabolism $\mathbf{8 1}$ 3740-3745.

Yip L, Cote GJ, Shapiro SE, Ayers GD, Herzog CE, Sellin RV, Sherman SI, Gagel RF, Lee JE \& Evans DB 2003 Multiple endocrine neoplasia type 2: evaluation of the genotype-phenotype relationship. Archives of Surgery 138 409-416.

Received 19 July 2004

Accepted 26 July 2004 